Sociologie et sociétés

\title{
La Russie à la rencontre de l'Amérique
}

(Frankfurter Zeitung, 23 novembre 1926)

\section{Russia goes to America}

\section{Joseph Roth}

Volume 45, numéro 2, automne 2013

URI : https://id.erudit.org/iderudit/1023185ar

DOI : https://doi.org/10.7202/1023185ar

Aller au sommaire du numéro

Éditeur(s)

Les Presses de l’Université de Montréal

ISSN

0038-030X (imprimé)

1492-1375 (numérique)

Découvrir la revue

Citer ce document

Roth, J. (2013). La Russie à la rencontre de l'Amérique : (Frankfurter Zeitung, 23 novembre 1926). Sociologie et sociétés, 45(2), 327-330.

https://doi.org/10.7202/1023185ar d'utilisation que vous pouvez consulter en ligne.

https://apropos.erudit.org/fr/usagers/politique-dutilisation/ 


\section{La Russie à la rencontre de l'Amérique}

(Frankfurter Zeitung, 23 novembre 1926)

JOSEPH ROTH

Traduction: Hélène Huetz de Lemps et Jürgen Heizmann

$\mathrm{Q}$

UICONQUE PARMI LES PAYS DE L'OUEST porte son regard vers l'Est afin d'observer le halo rouge d'une révolution intellectuelle, doit s'efforcer de se le projeter à l'horizon. Beaucoup font cet effort. Ce sont moins des révolutionnaires que les romantiques de la Révolution. Néanmoins, depuis longtemps, la Révolution russe a atteint l'état d'une certaine stabilité. Les lampions de la fête sonore et lumineuse sont éteints. Le quotidien, dégrisé, morne, pénible, a commencé. Mais une grande partie de l'élite intellectuelle de l'Ouest observe dans l'attente cette fameuse lumière venue de l'Est. La paralysie de la vie intellectuelle européenne, la brutalité de la réaction politique, l'atmosphère corrompue dans laquelle on génère et dilapide l'argent, l'hypocrisie des officiels, la splendeur illusoire des autorités, la tyrannie des anciens: tout cela oblige les libres penseurs et les jeunes gens à espérer plus de la Russie que la Révolution ne peut leur offrir. Comme ils se trompent! Qu'ils viennent ici et arpentent les rues ternes et sordides; qu'ils parlent à ces gens accablés qui sont sans cesse pris en étau entre une conférence, un achat de première nécessité au rabais et les crédits de consommation dans les magasins de l'État, qui moisissent dans des habitations ne cessant d'être menacées par les éternels procès des régies du logement, des habitations dans lesquelles les 
locataires vivent provisoirement comme dans des salles d'attente; qu'ils voient le laborieux appareil aux milliers de bras de ce gigantesque État - dans un mouvement continu, confus, parfois chaotique et vain. Peut-être verront-ils tout cela, mais ils croiront quand même qu'il y a ici le temps et la place pour les «problèmes» de l'esprit et l'extase. Les flambeaux de la Révolution sont éteints. Elle rallume les bonnes vieilles lanternes.

Bien nouveau était le spectacle rouge et grandiose de la révolution active. Mais à présent, ô camarades, l'heure de la contenance, utile et disciplinée est arrivée. Cette Russie-là n'a pas besoin de génies et encore moins de littéraires. Elle demande plus urgemment des instituteurs que de téméraires théoriciens; elle demande plutôt des ingénieurs que des inventeurs; davantage de constructions que de pensées; une actualité politique du moment et non idéologique, ce qui signifie: plus d'agitation que de tendance; elle a besoin d'usines et non de poètes; elle a besoin, pour les grandes masses, d'une hygiène populaire physique et mentale, celle que l'on nomme «les Lumières »; elle a besoin de livres et non d'œuvres. Les questions littéraires et culturelles sont ici du luxe. Les doutes deviennent suspects. Savoir différencier de subtiles nuances signifie ici adopter une idéologie bourgeoise.

Sont petits-bourgeois l'autodérision, les symboles, la floraison d'un esprit noble. La Révolution demeurait un engagement opulent de l'histoire, afin de rapprocher, au moins, la physionomie intellectuelle des masses russes à celle de l'Europe de l'Ouest. Sur les plans matériel, politique et social, c'était bien une révolution. Sur le plan intellectuel et moral, elle ne représentait qu'un énorme progrès quantitatif. Alors que chez nous devient pathologiquement banale une culture surannée et fanée par les girls, le fascisme et le romantisme superficiel, on trouve ici sainement banal un monde de puissance colossale fraîchement créé. Notre banalité décadente est confrontée à une banalité néo-russe, fraîche et regorgeante de santé.

Comment cela est-il possible? Voici la question que j'entends. Somme toute, nous lisons ici les dernières traductions fraîchement imprimées des jeunes auteurs russes. Somme toute, nous lisons Romanov, Seïfoullina, Babel! Oui, tous ces ouvrages, récents chez nous, appartiennent ici déjà au passé. Tous les jeunes et talentueux auteurs ne sont pas des révolutionnaires «disciplinés» comme on en aurait besoin; seulement quelques-uns sont communistes, d'autres n'approuvent pas la censure. Et tous les écrivains cherchent leurs sujets dans les premières années de la Révolution ou dans la grande époque de la guerre meurtrière et de la famine inhumaine. Tous les bons films, tels Potemkine, Mjat ou encore Wjeter (dont je parlerai plus tard), portent sur des épisodes révolutionnaires d'époques héroïques appartenant au passé lointain ou proche. Mais cette routine quotidienne, ces petites luttes fastidieuses au jour le jour, avec leurs millions de petits soucis monotones, qui ose la décrire, qui peut la décrire? L'heure des actes héroïques est révolue: nous vivons dans l'ère du travail de bureau assidu. L'heure des grandes épopées est révolue: nous vivons dans l'ère des statistiques.

Non seulement l'idée, mais aussi la construction du nouvel État, amorcée au nom de cette idée, force l'individualité à se comprendre comme facteur des masses. Mais 
alors qu'en tant que facteur des masses hautement intellectuelles, on ne doit pas nécessairement faire des compromis, et qu'on reste fidèle à tous, si lorsqu'on reste fidèle à soi-même; l'intellectuel, quant à lui, dans la Russie contemporaine, doit se sacrifier s'il veut servir la Révolution. Il ne se sacrifie pas à l'idéologie — ce ne serait pas un sacrifice - mais au quotidien. Un champ d'action plus large lui est assuré s'il reste à la surface au lieu d'aller dans la profondeur des choses. L'homme créateur, un révolutionnaire qui ne l'est pas par obligation comme l'est le prolétaire, sinon volontairement et par vocation, reste toujours un révolutionnaire - et ce, après de victorieuses révolutions. Il va certainement profiter du plaisir suprême de vivre dans un État qui veut l'émancipation de tous. Mais l'émancipation matérielle n'est qu'une des conditions les plus primaires de son existence. Il n'y a aucune forme de société qui pourrait s'attribuer, à la longue, la domination intellectuelle en dépit de l'aristocratie naturelle de l'esprit. L'aristocrate créateur n'a besoin ni de titre ni de trône. Mais c'est l'histoire et non la censure qui lui dicte ses lois.

Dans la Russie contemporaine, on doit malheureusement cultiver la médiocrité. On évite les sommets, on construit de larges allées militaires. C’est une mobilisation générale. Un marxiste fiable est bien plus précieux qu'un révolutionnaire audacieux. Une brique est plus utile qu'une tour. Des tracteurs! Des tracteurs! Des tracteurs! entend-on s'exclamer dans tout le pays. Civilisation! Machines! Abécédaires! Radio! Darwin! On méprise «l'Amérique», à savoir le capitalisme triomphant et sans âme, le pays dans lequel seul l'or est Dieu. Mais on admire aussi «l'Amérique», soit le progrès, le fer à repasser électrique, l'hygiène et l'eau courante. On veut les techniques de production parfaites. Résulte de ces aspirations une adaptation inconsciente à l'Amérique intellectuelle. Et ceci signifie le néant intellectuel. La grande culture européenne, l'Antiquité classique, l'Église romaine, la Renaissance et l'humanisme, une grande partie des Lumières et tout le romantisme chrétien: ils sont tous petits-bourgeois. Les anciennes réussites culturelles de la Russie: le mysticisme, l'art religieux, les manières et la culture de la cour, Tourgeniev et Dostoïevski: naturellement tous des réactionnaires. Alors, où donc prendre les fondements intellectuels pour un nouveau monde? Que reste-t-il donc? L’Amérique! L'esprit rationnel de l'Amérique, jeune, naïve, sportive, aseptisée sans l'hypocrisie du sectarisme protestant, mais avec la piété aveugle du communisme strict à sa place.

Aujourd'hui, en Russie, les magazines littéraires connaissent une incroyablement grande diffusion. Mais leur qualité en souffre. Chaque semi-lettré est capable de les lire. Mais le lecteur exigeant ne peut pas les lire. Le style utilisé par la plupart des jeunes écrivains russes en vogue est banal, à la portée de tous, ses éléments se composant de lettres de plomb dans leurs casses d'imprimerie. C'est une langue primitive et incapable de rendre exactement une quelconque nuance ou ambiance; elle est compréhensible de tous, mais aussi accessible à tous, un accoutrement de faits, de principes, d'agitation. Le nouveau théâtre (dont je parlerai plus tard) a atteint une perfection technique incroyable dans l'art de produire des effets. En revanche, la finesse de l'acteur s'y perd. Ce n'est pas l'atmosphère de la scène qui est évocatrice, mais les moyens 
techniques. La nouvelle peinture révolutionnaire se restreint aux métaphores qui n’ont pas la force de devenir des symboles. Des forces sont libérées par milliers, par millions. Un jour, elles allumeront probablement une lumière qui sera plus lumineuse que le feu de la Révolution. Mais pas maintenant ni même dans vingt ans. Pour le moment, la physionomie intellectuelle de l'Europe reste encore plus fascinante bien que sa physionomie politique et sociale soit terrifiante. 